\title{
FUENTES BIBLIOGRÁFICAS EN LA TRADUCCIÓN DE ANACREONTE Y DE MUSEO DE GRACILIANO AFONSO*
}

\author{
María Gloria González Galván - Francisco Salas Salgado \\ Universidad de La Laguna \\ maglogon@ull.edu.es - frasalas@ull.es
}

\begin{abstract}
RESUMEN
En este artículo estudiamos las referencias bibliográficas que se encuentran en la traducción de Anacreonte y de Museo realizada por el humanista Graciliano Afonso en el siglo XIX. Pretendemos además contextualizar estas fuentes en el marco general de la historia de la Filología clásica en ese momento.
\end{abstract}

Palabras Clave: Anacreonte, Museo, Traducción, Fuentes bibliográficas, Siglo XIX.

\section{ABSTRACT}

«Bibliographical sources in the translation of Anacreon and Museum by Graciliano Afonso». In this paper we study the bibliographical references found in the translation of Anacreon and Museum by the humanist Graciliano Afonso in the $19^{\text {th }}$ century. We also intend to contextualize these sources within the general framework of the history of Classical Philology at that time.

KeY WORDS: Anacreon, Museum, Translation, Bibliographic Sources, $19^{\text {th }}$ Century.

1. Es normal dentro de nuestro campo de estudio, la Filología Clásica — diríamos que hoy en día casi una exigencia- cumplir con la preceptiva relación de las obras (libros, artículos, ponencias, comunicaciones, etc.) que han servido para guiar y contextualizar una investigación determinada.

En épocas pasadas sucedía algo parecido, si bien los criterios que se seguían no eran en absoluto homogéneos. Las fuentes utilizadas de autores antiguos y modernos junto con las obras y estudios de referencia también tenían su lugar, pero no formaban una parte específica como en la actualidad. Normalmente aparecían referencias en los márgenes, como guía de lectura y, posteriormente, en las notas que, tanto a pie de página como al final de las composiciones, ya en prosa ya en verso, acompañaban a estas.

Aunque pueda parecer insubstancial investigar este tipo de cuestiones, lo cierto es que tiene una importancia capital (junto, claro está, con la catalogación, estudio y análisis de las bibliotecas públicas o privadas), especialmente para conocer el grado de conocimiento que se tenía de la Antigüedad y de la cultura grecolatinas 
y con ello completar esa historia de la filología clásica particular que se ha generado en cada región, dentro del marco general de la disciplina.

En efecto, si el estudio de las bibliotecas es fundamental para determinar los gustos lectores particulares y generales de una época determinada, en el caso de que no se pueda acceder a las mismas, ya sea directa o indirectamente (a través por ejemplo de los inventarios de bienes realizados post mortem), son estas anotaciones y referencias las que permiten el conocimiento de ello.

Estas apreciaciones tienen que ver muchísimo con el autor que vamos a tratar aquí, Graciliano Afonso Naranjo, destacado helenista y latinista ${ }^{1}$ canario perteneciente a una generación que creció y se desarrolló intelectualmente entre fines del siglo XVIII y la primera mitad del siglo XIX, participando de corrientes literarias tan diversas como la ilustración, neoclasicismo o prerromanticismo, cuyas características se plasman en las producciones que generaron.

2. Graciliano Afonso nació en La Orotava en el año 1775, y murió en Las Palmas de Gran Canaria en 1861. En ese extenso periplo vital la presencia de los clásicos, griegos y latinos, fue constante: sus traducciones de Homero, Sófocles, Anacreonte, Museo, Virgilio, Horacio, Catulo, etc., lo demuestran ${ }^{2}$. Pero, sobre todo, inciden en el interés vulgarizador de los clásicos que pretendía con la realización de las mismas, lo que puede explicar el hecho de que, cuando se ha analizado esta faceta desde el punto de vista estrictamente filológico, se observe cierta libertad en las mismas.

De entre estos autores vamos a tratar aquí, por razones de espacio pero sobre todo por la relación que guarda con la filología griega, la traducción que realizara de Anacreonte y de Los amores de Leandro y Hero de Museo. Esta traducción fue publicada en Puerto Rico, junto con la obra en vernáculo El Beso de Abibina ${ }^{3}$.

El profesor Marcos Martínez realizó hace unos años una amplia y documentada contextualización literaria en el marco general de la poesía anacreóntica y su relación con Afonso. Ofrecía además referencias sobre los vínculos que existían entre la producción de don Graciliano y el género anacreóntico, con mención a sus traducciones, a algunas composiciones en latín y en vernáculo, incluyendo un apéndice documental con composiciones relacionadas con este género literario. Apuntaba especialmente:

* Este trabajo se ha realizado en el marco del Proyecto "La erudición clásica entre la Ilustración y el Romanticismo: Graciliano Afonso y el comentario humanista" financiado por el Vicerrectorado de Investigación de la ULL (2017).

${ }^{1}$ Cf. Martínez, 2003; y Salas Salgado, 1989-1990; 1991; 2000-2001; 2008; 2011; 2013.

${ }^{2}$ Cf. Salas Salgado, 1999: II, 90-100.

${ }^{3}$ Si bien esta traducción fue publicada en la tercera década del siglo XIX, no está de más recordar el momento álgido que hubo en cuanto a traducciones en la última década del siglo XVIII en España, con un periodo de actividad muy alto entre 1788 y 1798. Recordemos que una de las versiones realizadas en este tiempo fue la traducción de Anacreonte de los hermanos Canga-Argüelles que Graciliano Afonso conoce y cita oportunamente. Cf. para más información Hernando (1975: 213-215). 
Como poeta anacreóntico, es la faceta principal de toda su actividad intelectual. Graciliano Afonso practica el idilio, la canción, la décima, el soneto, la letrilla, el romance (tanto heptasílabo, como octosílabo y endecasílabo), etc., pero es en la poesía de tipo anacreóntico en la que se desenvuelve con mayor soltura (Martínez, 2003: 93).

En efecto, una de las producciones que tiene que ver con esta clase de género, es la traducción mencionada de Anacreonte, que apareció publicada junto a la de Museo en la imprenta Dalmau, en el año 1838 (refiere Martínez [2003: 103], en clara errata, 1830). Se juntan aquí tres obras en un solo volumen, numerado de forma correlativa - lo que otorga cierta uniformidad_- aunque como se verá la fecha de edición de alguna de ellas no es la misma ${ }^{4}$. Por esas mismas fechas, un poco antes, también aparecía la obra Ancreonte, Safo y Tirteo, traducidos del Griego en prosa y verso, por Don José del Castillo y Ayensa de la Real Academia Española, Madrid, en la imprenta Real, 1832.

3. El contenido de esta edición puertorriqueña, con las obras que incluye y su descripción es la siguiente ${ }^{5}$ :

1) Traducción de Anacreonte:

Va precedida en preliminares tras la portada y sin numerar de una «Fe de erratas» con la Nota siguiente: «La circunstancia de ausentarse el autor de este país, no le permiten $(s i c)$ detenerse á hacer la correccion cual debia ser» ${ }^{6}$. A esta nota continúa un «Compendio de la vida de Anacreonte» (pp. 3-12), "Anacreon Traducido del Griego» (pp. 13-62).

2) Traducción de Museo:

Portada («Los Amores de Leandro y Hero de Museo. Traducido del Griego por G. A. 1837») + «Advertencia» (pp. 65-68) + «Los Amores de Leandro y Hero de Museo» (pp. 69-82).

3) El Beso de Abibina:

Portada («El Beso de Abibina por G. A.», p. 83) ${ }^{7}+$ «Al Sr. D. José Turull Menor» (poesía dedicatoria), pp. 85-86 + «Prólogo» (poesía), pp. 87-88 + «El Beso de Abibina» (pp. 89-141) ${ }^{9}$.

${ }^{4}$ Hemos seguido el ejemplar que se encuentra en la biblioteca de El Museo Canario, Las Palmas de Gran Canaria: sign. II-C/81.

${ }^{5}$ Adelantamos desde aquí que hemos respetado la ortografía, acentuación y la puntuación de esta edición, por otro lado plagada de erratas, que señalamos llegado el caso en las citas que realizamos de la misma.

${ }^{6}$ En efecto Graciliano Afonso gracias a la amnistía promulgada por la reina Cristina y su hija Isabel estará de regreso a Canarias por esas fechas. Esta nota y "La Fe de erratas" debieron hacerse en Puerto Rico.

${ }^{7}$ En la contraportada aparecen unos versos con la siguiente aclaración: "Quintana. Con. ${ }^{\text {on }}$ á Fileno". Se trata del literato Manuel José Quintana, y su obra "A Fileno. Consolándole en una ausencia".

${ }^{8}$ Al final: “S. A. G. A.” [= ¿'Su Amigo Graciliano Afonso?] Puerto-Rico Marzo 9 de 1838”.

${ }^{9}$ Con correcciones y añadidos a lápiz. 
4) «Nota de Anacreonte». Oda 3.- Cuando Bootes lucido (pp. 143-144) + «Nota sobre el Beso de Abibina» (p. 144).

Asimismo, la traducción de Anacreonte y las otras obras se hallan manuscritas, de letra de Juan de Padilla, en El Museo Canario de Las Palmas, concretamente en el tomo II de las Poesías de D. Graciliano Afonso, Doctoral de la Santa Iglesia Catedral de Canarias ${ }^{10}$. Como se verá enseguida, por la descripción de su contenido, difiere este manuscrito de la edición puertorriqueña citada antes por algunos añadidos que aparecen aquí. Consta así:

1) Traducción de Anacreonte (paginada correlativamente, pero con añadidos posteriores que se han numerado de forma diferente):

a) p. 155: [Portada] Odas de Anacreon II (Los Amores de Leandro y Hero II Traducidos del Griego || Y || El Beso de Abibina tachado) || Por || D. Graciliano Afonso, II Doctoral de Canarias. II Con permiso del Gobierno || Puerto Rico II Imprenta de Dalmau. II Año de 1838.

b) [p. 156]: [Nota] «La circunstancia de ausentarse el autor de este pais, no le permiten (sic) detenerse á hacer la correccion cual debia ser».

c) pp. 157-170: «Compendio de la vida II de II Anacreonte» [al fin: 1836].

d) pp. a.17-24: «Vida de Anacreonte»"

e) pp. a.1-15 «Breve discurso sobre la Poesia II Anacreontica» [al fin: «Palmas de Canaria Diciembre 30 de 1854»].

f) pp. 171-237: Anacreon II Traducido del Griego.

Aparecen numerosos reclamos, al margen, a lápiz y correcciones a tinta, así como correcciones encima de los versos. Por lo menos han intervenido tres manos: una mano la que escribe a lápiz con una letra de tamaño mayor, las correcciones que debieron realizarse al hilo de la copia de Juan de Padilla del siglo XIX ${ }^{12}$ y las correcciones realizadas a tinta sobre los versos y al margen, de fecha del siglo pasado.

g) pp. 238-240: Nota de Anacreonte. II Oda 3.-Cuando Bootes lúcido.

h) pp. 241- 242 (127): Notas II á las Odas de Anacreonte.

La paginación es errónea: $241+242+242(1)-242(127)$. Termina en Oda 64 sin nota, con lo cual se trata de una parte inconclusa ${ }^{13}$.

${ }^{10}$ EMC: Fondo Chil, Sección “Graciliano Afonso”, sign. Gch. 1652.

${ }^{11}$ En nota al comienzo: "Esta biografía [supra "fragmento" tachado] la dejo el autor sin terminar. El autor no terminó esta biografia».

${ }^{12}$ Juan Padilla Padilla nació en 1826 y murió en 1891 en Las Palmas de Gran Canaria. Fue miembro del primer Consejo de Redacción de la revista El Museo Canario, y colaborador eficaz del doctor Gregorio Chil y Naranjo. Gracias a su labor de copia conservamos muchos documentos para el conocimiento del siglo XIX canario. Cf. para otros datos Izquierdo (2005: III, 9).

${ }^{13} \mathrm{El}$ carácter de apéndice de estas páginas se demuestra en la anotación que aparece en p. 242 (128) que nada tiene que ver con los textos anteriores: «Se tomará acuerdo sobre una exposicion suscrita por gran número de vecinos encaminada a promover una reunion publica para deliberar lo procedente á objeto de conseguir nuestra independencia administrativa». 
2) Traducción de Museo:

a) p. 243: [Portada]: Los amores de Leandro y Hero II De Museo II Traducido del Griego || 1837. || Impreso en Puerto Rico II en I| 1838.

b) pp. 245-250: Advertencia

c) pp. 251- 270: Los Amores II de Leandro y Hero II de Museo.

Hay añadidos realizados al margen, a tinta, de determinadas palabras que aparecen en el original impreso, que suponen un cambio en la traducción (la letra parece ser de Juan Padilla). Otros fueron realizados a lápiz. A tinta también se añaden algunos versos a la traducción.

3) El Beso de Abibina:

a) p. 271: [Portada] El Beso || de || Abibina. || 1838. || Impreso en Puerto Rico. II Año de II 1838.

b) p. 272: [Versos de Manuel José Quintana].

c) pp. 273-274: Al D. ${ }^{\circ \mathrm{D}}$ D. José Turull II Menor. [Al fin: S.S.G.A. II Puerto Rico. Marzo 9 de 1838].

d) pp. 275-276: Prólogo.

Añadidos al margen.

e) pp. 277-349: El Beso de Abibina [Oda 1.a-Oda 27a] [Al fin: Puerto Rico y Marzo $1 .^{\circ}$ de 1838].

Añadidos al margen a tinta de letra de Padilla.

f) pp. 349-350: Nota [Al fin: años de 1837 (tachado)].

Como dijimos antes, si comparamos el impreso de Puerto Rico y el manuscrito es fácil observar que, sobre todo, en relación con la traducción de Anacreonte existen añadidos notables. Se puede intuir que Juan Padilla hubo de tener a la vista un texto ampliado que Graciliano Afonso habría realizado (se supone que pertenece a su estancia en tierras americanas), aunque el texto manuscrito de Padilla no refleje lo que el Doctoral manifiesta al final del «Compendio de la vida de Anacreonte». Aquí decía:

La traduccion, salió en cuatro columnas griegas, latinas, prosa y verso español con algunas notas que me parecieron indispensables; y asi existe una copia, que será impresa luego que el público haya manifestado su opinion sobre la presente. (Afonso, 1838: 10-11)

Cabe destacar también la importancia que tienen en este manuscrito las correcciones realizadas al texto de la traducción, que reclaman un análisis y estudio meticuloso. Evidentemente, la necesidad de una edición crítica es por tanto urgente ${ }^{14}$.

${ }^{14}$ M. Martínez (2003: 74) señalaba su intención de publicar, junto a G. Santana Henríquez, todas las versiones griegas de Graciliano Afonso sin que tengamos noticia alguna de su realización. 
4. Sin embargo, nuestra intención en este trabajo es otra, a pesar de la importancia de lo que acabamos de indicar. Pretendemos, sobre todo, por lo dicho al comienzo, documentar las fuentes que Graciliano Afonso cita en esta obra, algunas de las cuales seguramente le fueron de utilidad para realizar estas traducciones. Hay que tener en cuenta que esta labor la realizó fuera de las Islas, en el momento en que estaba en el exilio en tierras americanas, concretamente en Puerto Rico, alejado de toda comunicación cultural.

Se conoce poco de su destierro, si bien se sabe que esta etapa coincide con el comienzo de su actividad literaria. Alfonso Armas Ayala, uno de los primeros estudiosos de la obra de este humanista y escritor orotavense, comentaba:

Su vida americana es poco conocida: él mismo proporciona contadas noticias. Entre todas, una que debe destacarse: las primeras producciones literarias de Afonso están fechadas en Venezuela, Trinidad de Barlovento o Puerto Rico. Con anterioridad, muy poco se conoce de su pluma, aparte de sus informes doctorales, de las representaciones teatrales hechas en Las Palmas en 1821, de su satírica composición hecha a los 22 años con motivo del ataque de Nelson a Tenerife. El escritor surge en el destierro, en donde producirá su obra definitiva. Como tantos emigrados, encontró en la pluma un medio de hacer correr el tiempo, enemigo inexorable del desterrado. El encontrarse en tierras, rodeado de penuria y soledad, despertó al escritor. (1963: 172)

En efecto, las únicas lecturas a las que podía acceder Afonso en su estancia americana según Armas fueron las de periódicos, las escasas publicaciones que se hacían en esos lugares o «el feliz hallazgo de una biblioteca española, como ocurrió en la isla de Trinidad» (1963: 175).

Nuestro humanista dejó constancia de ello en las traducciones que aquí nos ocupan, cuando habla de la fortuna que tuvo de encontrar determinados libros, entre los que se encontraban algunos clásicos:

Emigrado en una Colonia inglesa hace doce años, lejos de comunicacion con literatos españoles, sin mas libros, que los pocos que podian hallarse en un pueblo naciente, y todo mercantil, reservados á personas de alto carácter; solo me podian servir de guia los recuerdos de mi juventud debilitados en la edad de 60 años: cuando en una Almoneda-pública encontré un Anacreonte en griego y latín de Gail; al punto resolví recordar mis antiguas lucubraciones griegas, que habian sido mi principal ocupacion en mi destierro con un Homero de Clark, y una Biblia, que hice venir de Londres [...] (Afonso, 1838: 9)

Lo mismo le ocurrió con la traducción de Museo, que comenzó en Trinidad de Barlovento, como se conocía entonces a la isla Trinidad:

[...] por casualidad en la Almoneda del Obispo Bockley V. G. App. ${ }^{\circ}$ de las Islas de Barlovento, residente, en la Trinidad, hallé y compré una malisima impresion de varios clasicos de aquel Idioma; y hallando por otra mayor rareza, un Boscán mutilado en las manos de un maniaco de la literatura Española, aunque Ingles, me puse en estado de exáminar (sic) lo que hacia mucho tiempo deseaba; [...] (Afonso, 1838: 65) 
5. Para observar cierta coherencia con lo que acabamos de decir, atenderemos únicamente aquí el texto de la edición americana relacionado con Anacreonte y Museo, esto es: «Compendio de la vida de Anacreonte» (anotado), «Advertencia» a la traducción de Museo y «Nota de Anacreonte»"

5.1. Entre esas fuentes cabe hacer una primera distinción que diferencia los autores clásicos de los autores modernos. La biografía de Anacreonte le permite a Afonso referir algunas de las fuentes griegas que han mencionado algo del autor griego, en este caso, Platón, Ateneo y la Suda, conocido léxico bizantino:

El alegre y festivo Anacreonte, parece estaba destinado á reglar las orejas de los tiranos, pues Hiparco hijo de Pysistrato, que heredó de su padre el amor á las letras con de la tiranía, envió, dice Platon ${ }^{16}$, una carta muy lisongera, y una galera con cincuenta remeros para conducirle á Athenas, poco antes de la terrible catástrofe de Policrates, para ser testigo de la otra no menos terrible, que prepararon los héroes, Armodio y Aristogiton, á Hiparco y á su hermano el traidor Hippias. Sin duda, que estas sangrientas escenas obligaron á nuestro Barda (sic) á tornar á Teos ya libre y repoblada por sus antiguos habitantes, despues de la muerte de Cyro. Aquí vivió, como dice Suidas, hasta que nuevos disturbios le impelieron otra vez á Abdera, en donde finalizó sus dias en la edad de 85 años. [...]. Si queremos descifrar el carácter de Anacreonte; encontramos las mismas dificultades; jera un disoluto y libertino, cual le anuncian sus versos? pero Atheneo ${ }^{17}$ le llama, Neras kai agathos, sobrio y respetable, y antes, Platon; el sabio Anacreonte ${ }^{18}$. (Afonso, 1838: 5-6)

5.2. La vinculación con la bibliografía de la época, o en su caso la que caracteriza la erudición clásica que posee este humanista, se observa en la referencia a ediciones y traducciones que debían ser en esas fechas las más novedosas y relevantes. La primera referencia es a Josuah Barnes ${ }^{19}$, quien había fijado el nacimiento de Anacreonte

\footnotetext{
${ }^{15}$ Nos ha sido de mucha utilidad la consulta en línea del Catálogo Colectivo del Patrimonio Bibliográfico Español (http://catalogos.mecd.es/CCPB/ccpbopac).

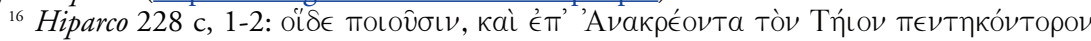

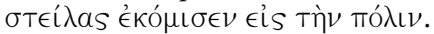

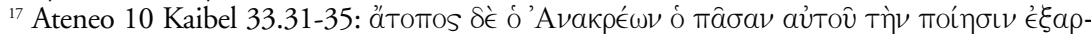

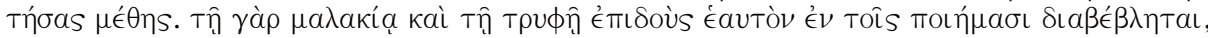

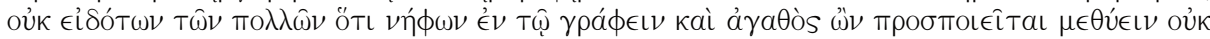

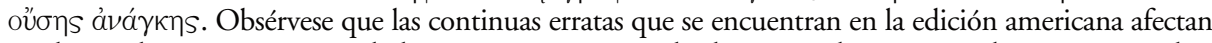
también a las transcripciones de los textos griegos: a todas luces, por la propia traducción que realiza incluso Afonso, «Neras» es una errónea transcripción de la palabra griega $\nu \eta ́ \phi \omega \nu$.

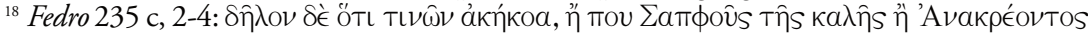

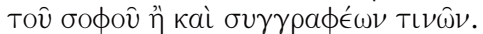

${ }^{19}$ Formó parte de una generación de filólogos ingleses de prestigio de la segunda mitad del siglo XVII. Tuvieron gran consideración sobre todo sus ediciones de textos griegos. Como nos indica Pfeiffer (1981: II, 243) junto a Barnes en esa generación se encontraban John Pearson, obispo de Chester, Thomas Stanley, editor de Esquilo y rival de Bentley como editor de Calímaco, Gale y Potter. Hernando (1975: 231) lo cita como Joseph Barnes e informa de que para su edición de Anacreonte, publicada en Cambridge, tuvo en cuenta versiones latinas y francesas.
} 
en el año segundo de la Olimpiada 55, o sea, "554 años antes de J.C. casi al principio del reyno de Cyro, y en el año de 194 de la fundacion de Roma» (Afonso, 1838: 3-4). Josuah Barnes fue autor de una edición de Anacreonte realizada en 1705 (también editó a Eurípides y a Homero) ${ }^{20}$.

Dos veces aparece la mención a M. Jean Baptiste Gail, profesor que fuera del Colegio de Francia. Así en la única nota que existe en esta edición, cuando trata del carácter libre y patriótico que caracterizó a Anacreonte, trae a colación el fragmento 37 recogido por Gail, y en la relación de traductores que habían vertido al autor griego los señala en primer lugar como autor de una traducción en prosa, aunque da noticias de otras versiones entre las que refiere la de los hermanos Canga-Argüelles:

¿Como pues traducir á Anacreonte: como trasmitir en los esfuerzos de una traduccion la gracia y la blandura de un canto de inspiracion, todo imagenes, todo sentidos, retratados en su divino idioma, en la pobreza y cequedad (sic) de nuestras lenguas modernas? Sin embargo de estas visible e insuperables dificultades hallamos traducciones de este poeta en latin, que están en casi todas las públicas bibliotecas, acompañados del texto griego, con grandes comentarios, que embarazan mas que ayudan la juventud, que los consulta. Entre las latinas, ultimamente ha aparecido la de M. J. B. Gail profesor de Lit en el Coleg de Francia, con una traduccion en prosa francesa, que es, á mi juicio la mas justa, y exacta de cuantas hasta ahora han caido en mis manos. Se halla traducido en verso frances, por Galou, Sivri, Lafosse y otros modernos: en italiano hay varias; y en ingles hay dos recientes, las de Moore y Bourne; [...] Yo ignoro si hay traduccion alguna en verso español mas antigua que la de D. Esteban Manuel de Villegas, y entre los modernos helenistas, alguno que haya adelantado sobre el ensayo de los hermanos Canga y Argüelles. (Afonso, 1838: 9-10).

J. B. Gail había realizado una edición de Anacreonte, donde aparecía el texto paralelo griego-latín ${ }^{21}$ y una edición con texto paralelo en griego y latín en las páginas pares y en francés en las impares ${ }^{22}$. Los otros traductores franceses que menciona son Antoine de La Fosse, poeta francés (París, 1653-París, 1708), quien tradujo las Odas de Anacreonte en $1704^{23}$; y Louis Poinsinet de Sivry, literato francés nacido

${ }^{20}$ Anakreontos Teiou Symposiaka emiambia, Anacreontis Teii Convivialia Semiambia, [aedibus Iosephi Spalletti; traductor Joshua Barnes], Romae: [s.n.], 1781, [12], LX p., con el texto paralelo en griego y latín.

${ }^{21}$ Anacreontis odae et fragmenta graece et latine edente Joanne Baptista Gail, Parisiis, typis Didot natu majoris, Apud J.-B. Gail, An. VII [1788].

${ }_{22}$ Odes d'Anacréon traduites en françois avec le texte grec, la version latine; des notes critiques, et deux dissertations par le citoyen Gail ... ; avec estampes, odes grecques mises en musique par Gossec, Méhul, le Sueur et chérubini, édition plus complete que toutes celles qui ont paru jusqu'à ce jour, a Paris, de l'imprimerie de Pierre Didot l'aîné, an VII [1798]. Antes, en 1794, apareció también en París y en la misma imprenta, Odes, inscription, épitaphes, épithalames et fragments d'Anacréon, traduits en français, avec des notes critiqus et un discours préliminaire, par le $C^{n}$ Gail.

${ }^{23}$ Esta traducción en verso aparece añadida ("nouvelle ed. aug. de notes latines de Mr. Le Febre \& de la traduction en vers françois de Mr. de la Fosse") a la de Dacier (Les poesies d'Anacreon et de Sapho traduites en françois avec des remarques par Mademe Dacier, a Amsterdam, chez La Veuve de Paul Marret, 1716). 
el 20 de febrero de 1733 en Versalles y muerto en 1804 en París, que realizó y parafraseó en verso a Anacreote, Bion, Mosco y Safo y otros poetas griegos (1756, en doceavo $)^{24}$.

Sin embargo, no hemos podido encontrar referencia alguna a Galou, escrito de esta manera. Aceptando que se trate de otra errata, las cuales llenan este impreso (habría que insistir de nuevo en que esta traducción no fue corregida por Graciliano Afonso), por coincidencia gráfica el traductor con el que guarda gran parecido y del que consta que realizó traducciones de Anacreonte es François Gacon ${ }^{25}$.

Por su parte, Thomas Moore había trasladado a Anacreonte en verso inglés, con notas, (Londres, 1806) en dos volúmenes, y la traducción de Thomas Bourne apareció publicada también en Londres en 1830. En fin, las Obras de Anacreonte traducidas del griego en verso castellano, por D. Joseph y D. Bernabé Canga Argüelles aparecieron en Madrid (Imprenta de Sancha) en $1795^{26}$.

De Museo particularmente refiere la traducción de Boscán, texto que había leído de joven ${ }^{27}$. Su intención desde entonces, tras conseguir el texto griego, era compararla con el original. Las cualidades de la obra de Museo le da pie asimismo para hacer mención a uno de los filólogos más conocidos, Julio César Escalígero ${ }^{28}$ :

Joven, leí la traduccion de Boscán de los amores de Leandro y Hero, en verso suelto ó blanco; y careciendo entonces, y aun despues, del original Griego, nunca pude compararla para graduar su mérito: por casualidad en la Almoneda del Obispo Bockley V. G. App. ${ }^{\circ}$ de las Islas de Barlovento, residente, en la Trinidad, hallé y compré una malisima impresion de varios clasicos de aquel Idioma; $\mathrm{y}$ hallando por otra mayor rareza, un Boscán mutilado en las manos de un maniaco de la literatura Española, aunque Ingles, me puse en estado de exáminar (sic) lo que hacia mucho tiempo deseaba; esto es si merecia tantos elogios la Obra de Museo, que Scaligero prefiere á Homero, y como, en el reciente Idioma poético Español y su endecasílabo sin consonantes habia trasladado sus gracias el amigo del inmortal Garcilaso. (Afonso, 1838: 65).

${ }^{24}$ Cf. Hoefer, 1862: 559.

${ }^{25}$ Les odes d'Anacreón et de Sapho en verso François, par le pöete sans fard (François Gacon), Rotterdam, Fritsch et Böhm, 1712. También hay edición en Paris (Grangé) en 1754. Cf. Catalogue (1899: col. 1115).

${ }^{26}$ Cf. Rodríguez-Alonso, 1984-85: 232-233.

${ }^{27}$ La Historia de Leandro y Hero, primer poema español en verso libre de tema mitológico, aparecía en el tercer tomo de las Obras de Boscán y algunas de Garcilaso, publicadas en 1543 en Barcelona por su viuda, junto a la Epistola a Mendoza, y la Octava rima.

${ }^{28}$ En efecto como dice A. López Eire (2007: 27, n. 41) Escalígero «consideraba que Museo, el poeta tardío autor del poema Hero y Leandro, a quien él confundía con el legendario poeta Museo, de la misma mítica generación de Orfeo, era superior a Homero (Poética V, 2) y afirmaba que ningún dramaturgo griego había compuesto tragedias de mayor calidad que las de Séneca. Con este juicio se explica, en parte, la alta estimación en que tenían a las tragedias de Séneca determinados dramaturgos europeos de la Edad Moderna, como Shakespeare y Corneille». 
5.3. Las otras referencias bibliográficas que se citan no tienen que ver con el texto griego que se traduce, sino con otras disciplinas relacionadas. En efecto en la única nota que hay en esta edición referida al verso primero de la «Oda 3», se menciona al personaje de Bootes, aunque excusa dar referencias sobre este, remitiendo al lector a determinados manuales comunes en la época, como eran «los compendios de la Fábula de Chompré, Pomey y de Noël» (1838: 143) ${ }^{29}$. Lo mismo ocurre con las costumbres y usos que existían en la época de Anacreonte, datos y noticias que se hallan reunidos en «en el Diccionario de los clásicos de Lampriere, tan facil de adquirir y manejar» $(1838: 143)^{30}$; al igual que recomienda, para percibir las bellezas de algunas odas, sus imágenes, estilo y lenguaje, alguna poética, entre ellas «la del Sr. Martínez de la Rosa, ó en uno de tantos cursos de literatura y más que todos, en la coleccion del Sr. Quintana cuando habla de Villegas» (Afonso, 1838: 143-144)

5.4. En otras ocasiones la referencia a autores y obras, en este caso de otras lenguas, no se hace en relación al texto de la obra de Anacreonte, sino, como vamos a ver enseguida, atendiendo a determinadas peculiaridades, en este caso la personalidad del autor clásico y las ideas religiosas de los griegos:

Mas libres Poetas hemos tenido en estos últimos tiempos, sin hablar de los antiguos, La Fontaine y Grecourt en sus cuentos, Piron en sus odas y epigramas, Voltaire en su Pucelle, Parny y otros. [...] Los Griegos, si los medimos y calculamos por nuestras ideas, y las costumbres modernas, serán enteramente diferentes de lo que ellos fueron en la ópoca (sic) en que existían. Su religion y las costumbres tan lejanas de las nuestras, los constituyen, comparados con las cristianas, seres monstruosos; cual los pinta San Agustin, en su ciudad de Dios: [...] (Afonso, 1838: 6) ${ }^{32}$.

${ }^{29}$ Étienne Chompré, Dictionnaire abrégé de la fable, Paris, 1727; François-Joseph Michel, Abrégé de la mythologie universelle, ou dictionnaire de la fable, París, 1804; F. Pomey, Pantheum Mythicum, seu fabulosa deorum historia, Lyon, 1659.

${ }^{30}$ Se refiere a John Lemprière, Classical dictionary, containing a copious account of all proper names mentioned in ancient authors, with the value of coins, weights, and measures used among the Greeks and Romans and a chronological table. De esta obra se hicieron muchas ediciones (por ejemplo, London, Printed for T. Cadell and W. Davies, 1809, $7^{\mathrm{a}}$ ed.).

${ }^{31}$ Poetica, Palma, [s.n.], 1831 (imprenta de Guasp). Manuel José Quintana había dado a la luz en 1808 la Colección de poesías selectas castellanas, desde el tiempo de Juan de Mena reimpresa muchas veces, en la que aparecen las «Poesías de D. Manuel Esteban de Villegas» con una crítica severa.

${ }^{32}$ Se refiere a Jean de la Fontaine quien empezó a publicar sus primeros cuentos en 1644 de los cuales constan muchas ediciones; Jean B. Joseph Willart de Grecourt (Tours, 1683-Tours, 2 de abril de 1743); Alexis Piron (Dijon, 9 de julio de 1689- París, 21 de enero de 1773); la Pucelle d'Orleans de Voltaire aparecida en París en 1752; y Évariste-Désiré de Forges (vizconde de Parny). Por su parte San Agustín en su De civitate Dei señala en varias ocasiones esa circunstancia que refiere Afonso. $C f$. de esta obra por ejemplo I, 4,1-3; o III, 1-5. 
Ocurre así también cuando menciona el "curso de literatura» de La-Harpe (Afonso, 1838: 7) 33 $^{33}$ al referirse al carácter entusiasta de Anacreonte, quien buscaba el placer antes que otra cosa, y aborrecía los negocios y cuidados del mundo; y se refiere, además, a Giraldi, quien «en su historia de los poetas nos dice, citando los antiguos, que Anacreonte poseia una mediana fortuna y mucho desinterés» (Afonso, 1838: 8$)^{34}$.

5.5. Distintos autores y obras más generales aparecen citados, que sin embargo tienen una relación menor, a veces tangencial, con la lengua y la literatura griegas, muchas veces ni siquiera tienen que ver con estudios particulares sobre estos autores griegos traducidos, ni ofrecen datos sobre características antropológicas o costumbres sociales y religiosas. Es el caso de las referencias que hace sobre el género anacreóntico y los mejores autores de este género de composiciones ${ }^{35}$, o cuando habla del metro que pretende usar en la versión de Museo, el endecasílabo sin consonantes ${ }^{36}$.

6. Puestos a realizar una valoración de las fuentes mencionadas entendiéndose que esto se hace desde la provisionalidad que hay que observar cuando se trata de un estudio muy concreto, creemos que es imprescindible conocer los derroteros por los que transitaba la filología clásica en estos momentos para contextualizar la labor reali-

${ }^{33}$ Se señala en Hoefer (1859: 883) sobre esta obra: «La Harpe avait fait imprimer de son vivant douze volumes de cet important ouvrage; après sa mort on en ajouta quatre. Depuis cette époque le Cours de Littérature a été plusieurs fois réimprimé; parmi ces éditions la plus complète este celle de Firmin Didot, 3 vol. grand in $-8^{\circ}$; elle contient de nombreux suppléments empruntés aux ouvrages de Louis Racine, de Chénier, et de MM. Saint-Marc, Philarète Chasles, Boissonade, Dunlop, Buchon; on distingue aussi l'excellente édition donnée par $\mathrm{M}$. Buchon et précédée d'un discours préliminaire sur la vie de La Harpe, sur ses ouvrages et spécialement sur son cours de littérature par Daunon; 1825-1826, $18 \mathrm{vol}$ in $-8^{\circ}$ ».

${ }^{34}$ Historiae poetarum tam Graecorum quam Latinorum dialogi decem, quibus scripta \& uitae eorum sic exprimuntur ..., L. Greg. Gyraldo ferrariensi autore, Basileae, [s.n.], 1545.

${ }^{35}$ «No son comunes las Anacreonticas en los modernos poetas españoles; contadas son en Cadalso, Cínfuegos (sic), Arriaza, Saavedra, Tapia; raras, muy raras en el cantor del mar, de la hermosura, y Juan de Padilla. Los maestros conocen, como Horacio, que es muy dificil, dar á las cosas comunes un tono particular, que las haga interesantes; [...]» (1838: 12). Cabe indicar que el canto del mar era una obra de Manuel José Quintana y el de la hermosura de Juan Meléndez Valdés.

${ }^{36} \mathrm{El}$ interés que tiene en probar la utilidad de este metro, poco usado por los poetas españoles (menciona a Garcilaso, Villegas, Juan de Jáuregui, Quintana, Meléndez Valdés, la Conquista de Granada de José María Vaca de Guzmán, esto es, la Granada rendida o El Moro Expósito de Ángel de Saavedra) lo fundamenta en el buen resultado que ha tenido su uso en obras diversas de países diferentes. Así en el Pastor Fido de Guarini, el Paraíso perdido de Milton, la Oda al Crepúsculo (Ode to Evening) de William Collins; o en los «Italianos, Alfieri, en sus Tragedias; Monti en las suyas; en su traduccion de la Iliada Pindemonte; Alejandro Manzzoni, en el Conde de Caramagnola; Silvio Pelico en su Francesa (sic por Francesca) de Rímini, y cuantos le han seguido no usan de otro metro.» (1838: 67). 
zada en este sentido por el Doctoral canario, algo que puede parecer que no tiene sentido pero que a poco que nos fijemos resulta imprescindible (recordemos como paréntesis que Graciliano Afonso fue un clérigo defensor y cultivador de las humanidades, como también lo fueron los mayores defensores de la tradición clásica a finales del siglo XVII en Inglaterra: Swift, Berkeley y Bentley).

Un resumen que nos ha parecido todavía útil es el que ofrece Wilhelm Kroll (1928: 136-137). La afirmación como ciencia de la filología clásica, debida al ingenio alemán, superando la concepción que se tenía antes, ocurrió según este autor sobre todo por la ayuda de algunos movimientos que tuvieron lugar en el siglo XVIII, en concreto, la Revolución, el Neohumanismo y el Romanticismo. El primer movimiento, donde tuvieron gran presencia los literatos franceses, propició la separación de la Filología Clásica de la Teología (así los autores griegos como Homero ya no se verían bajo la óptica, por ejemplo, de Virgilio, Séneca o Corneille). Esto hizo que el Neohumanismo mantuviera un ideal distinto para la formación cultural y artística, en un afán de mejorar el mundo bajo la regeneración que suponía el clasicismo griego. Por su parte, el movimiento romántico realizó un intento de comprender el arte y la literatura nacionales «juzgando las peculiares características de cada país y cada pueblo, acechando las conmociones inconscientes del alma popular» lo que favoreció que se empezara a comprender en profundidad el lenguaje y la religión.

Este contexto permite entender la amplitud de contenidos que se observan en las referencias bibliográficas que realiza Graciliano Afonso, no necesariamente vinculadas al texto de los autores griegos traducidos pues sobrepasan el marco de la filología clásica. La erudición que demuestra el Doctoral deriva de una formación y preparación humanística heredera del siglo de las Luces, pero su actividad se desarrolla en el momento en el que la Filología Clásica se asentó como ciencia en el siglo XIX, en ese concepto de "Altertumwissenschaft», acuñado por F. A. Wolf, que pretendía un carácter global para los estudios clásicos (Pfeiffer, 1981: II, 30). Y ese carácter global seguramente implicaba también un conocimiento global de la disciplina, de las obras relacionadas con la materia de estudio. Pudiera esto explicar que las referencias que se hacen en estas traducciones sean a obras realizadas en Inglaterra, pero sobre todo en Francia (poco hay sobre traducciones y estudios españoles, aunque haya que reconocer que señala los más importantes).

Todavía se percibe la huella de un principio de autoridad que se resiste a desaparecer, pero muestra Afonso cierta actitud crítica en sus comentarios especialmente en la elección (y selección) de determinadas fuentes. Aunque siempre esté presente como una espada de Damocles la posibilidad de que estas fuentes no provengan de una lectura (o conocimiento) directa de las mismas, sino que se hagan de forma trasversal, es destacable el conocimiento diverso del que hace gala nuestro humanista y la capacidad para enlazar de forma asombrosa autores y obras de épocas tan diversas.

\section{REFERENCIAS BIBLIOGRÁFICAS}

Afonso Naranjo, G. (1838): Odas de Anacreon. Los Amores de Leandro y Hero, traducidos del griego; y el Beso de Abibina por G.A. D. de C. 
Armas Ayala, A. (1963); Graciliano Afonso, un prerromántico español. Separata de «Revista de Historia Canaria», julio-diciembre de 1957 a enero-diciembre de 1962, La Laguna.

CATALOGUe Général des libres imprimés de la Bibliothèque Nationale, Paris, Imprimerie Nationale, 1897-1981. 231 vols.

GonZÁLEZ GonZÁLEZ, M. (2013): «Aproximaciones al estudios de la mitología en la España del XVIII y comienzos del XIX», en F. GarCía JuRAdo-R. GonZÁlezZ Delgado- M. GonZÁleZ GonZÁleZ (eds.), La historia de la Literatura Grecolatina en España: de la Ilustración al Liberalismo (1778-1850), Analecta Malacitana, Anexo XC, pp. 211-223.

HeRnANDO, C. (1975): Helenismo e Ilustración. El griego en el siglo XVIII español, Fundación Universitaria Española, Madrid.

HoefFer, J. CH. F. (ed.) (1855-1866): Nouvelle biographie générale depuis les temps les plus reculés jusqu'a nos jours, avec les renseignements bibliographiques et l'indication des spurces a consulter, publiée par MM. Firmit Didot Fréres, sous la direction de M. le D. ${ }^{r}$ Hoeffer, Paris, Imprimeurslibraires de l'Institut de France.

IZQUIERDO, E. (2005): Periodistas canarios, siglos XVIII al XX: propuesta para un diccionario biográfico y de pseudónimos, Islas Canarias, dirección General del Libro, Archivos y Bibliotecas. 3 vols.

KROLL, W. (1928): Historia de la Filología Clásica, trad. de P. GALINDO Romero, Editorial Labor, Barcelona.

LÓpez EIre, A. (2007): «Aproximación a la poética de Julio César Escalígero», Ágora. Estudos Clássicos em Debate 9.1: 11-49.

Martínez, M. (2003): «Un anacreóntico canario: Graciliano Afonso», en E. Padorno - G. SANTANA HENRíQuez (eds.), Ilustración y pre-romanticismo canarios: una revisión de la obra del Doctoral Graciliano Afonso (1775-1861), Excmo. Ayuntamiento de Arucas - Fundación Mapfre Guanarteme de Arucas - Servicio de Publicaciones de la Universidad de Las Palmas de Gran Canaria, Las Palmas de Gran Canaria, pp. 69-144.

PfeIfFer, R. (1981): Historia de la Filología Clásica, Gredos, Madrid. 2 vols.

Rodríguez Alonso, C. (1984-1985): «Los hermanos Canga-Argüelles, helenistas asturianos del siglo XVIII», Archivum 34-35: 227-250.

SAlas Salgado, F. (1989/1990): «La versión de la Eneida de Graciliano Afonso», RFULL 8/9: 319-337.

- (1991): «Acercamiento formal a un poema latino del siglo XIX en Canarias: el In promptu de Graciliano Afonso", Fortunatae 2: 297-312.

- (1999): Humanistas canarios de los siglos XVI a XIX. T. I. Contexto Histórico-literario. T. II. Catálogo biobibliográfico, Servicio de Publicaciones de la Universidad de La Laguna, La Laguna.

- (2000-2001): «La huella de Catulo en el Beso de Abibina de Graciliano Afonso: a propósito de la Oda 11", Fortunatae 12: 227-238.

(2008): La traducción de la Eneida de Graciliano Afonso (1853). Introducción, edición y notas, Gobierno de Canarias - Anroart Ediciones, Las Palmas de Gran Canaria.

(2011): «La adecuación de las estructuras en la traducción de la Eneida de Graciliano Afonso», Calamus renascens: Revista de humanismo y tradición clásica 12: 167-184.

(2013): «Sobre la redacción de la Eneida de Virgilio traducida por Graciliano Afonso», Bulletin Hispanique 115.1: 285-304. 
